\title{
Assessment of level of knowledge and utilization of emergency contraception among female students of Hawassa University, south Ethiopia*
}

\author{
Ejara Tolossa ${ }^{1}$, Birhan Meshesha ${ }^{1}$, Amanuel Alemu Abajobir $^{2 \#}$ \\ ${ }^{1}$ College of Health Sciences, Hawassa University, Hawassa, Ethiopia \\ ${ }^{2}$ College of Health Sciences, Debremarkos University, Debremarkos, Ethiopia; ${ }^{\#}$ Corresponding Author: amanuel_alemu@yahoo.com
}

Received 22 July 2013; revised 30 August 2013; accepted 9 September 2013

Copyright (C) 2013 Ejara Tolossa et al. This is an open access article distributed under the Creative Commons Attribution License, which permits unrestricted use, distribution, and reproduction in any medium, provided the original work is properly cited.

\section{ABSTRACT}

Introduction: Emergency contraception is used as an emergency procedure to prevent unintended pregnancy secondary to an unprotected sexual intercourse and method failure. Hence, this study assessed the level of knowledge and utilization of emergency contraception among undergraduate regular female students of Hawassa University, south Ethiopia. Methods: An institution-based cross-sectional survey was conducted among female students of Hawassa University in December 2012. Seven hundred seventy six of the students were sampled by using multistage sampling technique. Pre-tested structured questionnaire was used to collect the data. Results: The majority 719 (92.7\%) of female university students ever had sexual intercourse and $17(2.2 \%)$ experienced forced sex. Eight $(47 \%)$ of these 17 students experienced unintended pregnancy all of which resulted in an induced abortion. Three hundred seventy nine $\mathbf{( 7 2 . 2 \% )}$ of the respondents had knowledge about emergency contraceptives and only $41(10.8 \%)$ of them had ever used emergency contraceptives; oral contraceptive pills were the most widely used form of all emergency contraceptives 41 (10.8\%). Age, marital status and age at menarche were associated with knowledge of emergency contraception; moreover, residence, year of study and experience of forced sex were found to be predictors of emergency contraception utilization. Conclusion: Female university students had been experiencing high rate of unintended sexual practice and pregnancy, low knowledge level and uti-

*Conflict of interest: These authors do not have any conflict of interest. lization of emergency contraceptives; moreover, they had no youth-friendly access to the services. Therefore, there is a need for collaborated effort to improve service access and scale up their utilization level to prevent unwanted pregnancy.

Keywords: Emergency Contraception; Knowledge; Utilization; Female Students; Ethiopia

\section{INTRODUCTION}

The world health organization (WHO) estimated that 210 million pregnancies occur each year of which 38\% are unwanted and $22 \%$ end up with abortion. Nearly 5.5 million African women have unsafe abortion, 36,000 of them die from the complication, while a million or more experience short- or long-term illness and disability [1,2]. Unwanted pregnancies were due to contraception nonuse, miss use and method failure [3].

Emergency contraceptives (EC) are the only one that can be used after unprotected sexual intercourse, offering a second chance to prevent unwanted pregnancy [4]. There are various methods of ECs including hormonal contraceptive pills and intrauterine contraceptive devices. If emergency contraceptives are widely used, unwanted pregnancy and the need for induced abortion could substantially reduce; they prevent women's risk of becoming pregnant from a single act of intercourse by $79 \%-99 \%$ [5].

Unmet need of family planning (FP) is highest among women 15 - 19 age group and $6 \%$ of all maternal deaths were attributable to complications of abortion due to unwanted pregnancy [6].

Ethiopia has the $5^{\text {th }}$ highest number of maternal death in the world; 1 in 27 women die from complications of pregnancy or child birth annually. Low level of contraceptive use leads to high levels of unwanted pregnancy 
and is the main cause of abortion. In 2008, 101 unintended pregnancies occurred per 1000 women aged 15 - 44 and $42 \%$ of all pregnancies were unintended [7]. Unwanted pregnancy is one of the most commonly observed reproductive health problems in Ethiopia [8].

Reduction of maternal mortality is one of the major goals of several countries and has been included in the Millennium Developmental Goals (MDGS) to mitigate $20 \%$ reproductive and sexual ill-health among women. Adolescents or youth in and out of school are highly vulnerable to unintended pregnancy and its complications.

According to EDHS 2011 in Ethiopia, the levels of maternal and infant mortality are among the highest in the world 676/100,000 LB and 59/1000 LB respectively [8]. Emergency contraceptive methods can prevent 75\% of expected pregnancies after unprotected intercourse (sexual violence), method failure or incorrect method use. However, misconception and lack of knowledge about ECs are common among both FP providers and clients.

Thus, this study was designed to assess the level of knowledge and utilization of emergency contraceptives and identify associated factors among undergraduate regular female students of Hawassa University.

\section{Methods}

\subsection{Study Area, Period and Design}

An institution-based cross-sectional survey was conducted in Hawassa University, one of the largest higher learning institutions in Ethiopia, from $12^{\text {th }}-26^{\text {th }}$ December 2012 .

\subsection{Source and Study Population}

All Hawassa University undergraduate regular female students and sampled female students were the source and study population respectively.

\subsection{Sample Size Determination}

The study used a single proportion determination formula with the proportion of students having awareness of emergency contraceptive to be $35.6 \%$ [9].

$$
\mathrm{n}=\frac{\mathrm{Z}(\alpha / 2)^{2} \mathrm{p}(1-\mathrm{p})^{*} \mathrm{D}}{\mathrm{d}^{2}}
$$

Where, $\mathrm{n}=$ the required sample size

$\mathrm{d}=$ desired precision $(5 \%)$

$\mathrm{D}=$ design effect (2 stages)

$\mathrm{P}=$ proportion of students having awareness of emergency contraceptive to be $35.6 \%$

$\mathrm{Z} \alpha / 2=1.96$ at confidence level 95\%

Therefore, $\mathrm{n}=3.84 \times 3.840 .356 \times 0.644 \times 2 / 0.0025=$ 705.
Thus, the required sample size was 705; adding $10 \%$ non-respondent rate the final sample size was 776 undergraduate regular female students.

\subsection{Sampling Procedure}

The needed number of sample was allocated proportionally among three campuses of the University (main campus, college of agriculture and college of medicine and health sciences). Multistage sampling technique was used; random sampling was used taking the attendance list as a sampling frame to reach to each study unit. Pretested structured self-administered questionnaire was used to collect the data from the study subjects.

\subsection{Data Collection Procedure}

Students from randomly selected departments and year of study from each department were included in the sampling. The selected students were taken to hall or class room where they were informed about the purpose of the study, importance of their participation and verbal consents were ensured. Based on their willingness to participate in the study, they were provided the questionnaire and filled and returned the data to the data collectors.

\subsection{Data Quality Control}

One-tenth of the data collection instrument was pretested. Moreover, data collectors were adequately trained on how to administer the questionnaire. Supervision was carried out by the principal investigators throughout the data collection period. After data collection each questionnaire was checked for completeness and consistency.

\subsection{Data Collection Tools}

Structured self-administered questionnaire was developed in English and translated to Amharic (local language); it contained three parts: socio-demographic and academic characteristics, sexual and reproductive history and variables related to knowledge andutilization of emergency contraceptive methods.

\subsection{Data Analysis}

Data were cleaned, edited, coded and entered into SPSS windows version 20 software. Frequencies were used to check for missed variables and error. Any error indicated at this time was corrected by revision of the original questionnaire; frequencies, percentage and summary statics were calculated to explain the study population in relation to relevant variables. Association between dependent and independent variables were assessed and presented using binary and multiple logistic regressions. To measure internal consistency, p-values less than 0.05 
were considered to be statistically significant in all cases.

\subsection{Study Variables}

\section{Dependent variables:}

- knowledge and utilization of emergency contraceptives

Independent variables

- socio-demographic characteristics

- sexual and reproductive history and

- variables related with knowledge and utilization of emergency contraceptive methods

Operational definitions

- Emergency contraception: type of contraception used as an emergency to prevent unwanted pregnancy following an unprotected or unintended act of sexual intercourse.

- Knowledge: awareness of the presence of the methods, type of emergency contraceptive methods, their sources, drug content and the ability to identify when to take emergency contraceptives after unprotected sex, emergency contraceptives' mechanism of action, side effects, legal status and effectiveness of emergency contraceptives to prevent unwanted pregnancy.

- Utilization: ever use of emergency contraceptives on the basis of their knowledge when the subjects were exposed to unprotected sexual intercourse to prevent unwanted pregnancy.

- Unprotected sexual intercourse: is an intercourse taking place without barriers methods.

- Sexual practice: ever had heterosexual intercourse.

\subsection{Ethical Consideration}

Ethical clearance was taken from institutional review board of Hawassa University and letter of permission was written to student deans and registrar offices of each campus. The students were informed about the objectives and purposes of the study and consent was taken from each respondent. Also they were informed about their right not to participate in the study or withdrawing at any time. Confidentiality of the information was assured at any level.

\section{RESULTS}

\subsection{Socio-Demographic Characteristics of Respondents}

The response rate was $100 \%$. The age-group of 20 years and above constituted 463 (59.6\%) of the respondents. More than half 425 (54.8\%) were Orthodox Christians. About three quarters (74.7\%) were single and 677 $(87.2 \%)$ of the respondents were living in the campus (Table 1).

\subsection{Sexual and Reproductive Characteristic of the Respondents}

More than two-third of the participants 552 (71.1\%) were reported to have had menarche at the age of 11 - 13 years. The majority 719 (92.7\%) of the respondents have had sexual intercourse in their life time. Of those who ever had sexual intercourse, about 702 (90.5\%) were by the consent of the female, while 17 (2.2\%) were forced sex. A total of 308 (39.7\%) reported that they have encountered forced sex and escaped from the attempt of forced sex once/more times. Of those who had forced sex, 14 (82.3\%) and $3(17.7 \%)$ were committed by their student boyfriends and teachers respectively. About 60\% forced sex took place in the hotels. From those who have encountered forced sex, 8 (47\%) students experienced unwanted pregnancy and all of them underwent induced abortion. In the period of 2010 - 2012 academic year, 82.3\% of the students experienced forced (Table 2).

\subsection{Knowledge and Utilization of Modern Contraceptive Methods}

Four hundred ninety one (63.3\%) of the students have knowledge about modern contraceptives. Oral contraceptive pills were the most common known methods by re-

Table 1. Socio-demographic and academic characteristics of Hawassa University female students, south Ethiopia, December 2012.

\begin{tabular}{|c|c|c|}
\hline Variables & Number $(n=776)$ & Percent \\
\hline \multicolumn{3}{|l|}{ Age (years) } \\
\hline $15-19$ & 313 & 40.4 \\
\hline $20+$ & 463 & 59.6 \\
\hline \multicolumn{3}{|l|}{ Religion } \\
\hline Orthodox & 425 & 54.8 \\
\hline Muslim & 146 & 18.8 \\
\hline Catholic & 41 & 5.3 \\
\hline Protestant & 135 & 17.4 \\
\hline Others & 29 & 3.7 \\
\hline \multicolumn{3}{|l|}{ Marital status } \\
\hline Single & 580 & 74.7 \\
\hline Married & 174 & 22.4 \\
\hline Divorced & 21 & 2.7 \\
\hline Widowed & 1 & 0.13 \\
\hline \multicolumn{3}{|l|}{ Residence } \\
\hline In-campus & 677 & 87.2 \\
\hline Out-of-campus & 99 & 12.8 \\
\hline \multicolumn{3}{|c|}{ With whom do you live $(n=99)$} \\
\hline With parent & 35 & 35.4 \\
\hline With peer in rent house & 33 & 33.3 \\
\hline Alone in rent house & 12 & 12.1 \\
\hline With husband & 19 & 19.2 \\
\hline \multicolumn{3}{|l|}{ Year of study } \\
\hline Year-1 & 270 & 34.8 \\
\hline Year-2 & 243 & 31.3 \\
\hline Year-3 & 141 & 18.2 \\
\hline Year-4 & 107 & 13.8 \\
\hline Year $>/=5$ & 15 & 1.9 \\
\hline
\end{tabular}


Table 2. Sexual and reproductive characteristics of Hawassa University female students, south Ethiopia, December 2012.

\begin{tabular}{|c|c|c|}
\hline Variables & Number (n & Percent \\
\hline \multicolumn{3}{|l|}{ Age of menarche (years) } \\
\hline $11-13$ & 552 & 71.1 \\
\hline $14+$ & 224 & 28.9 \\
\hline \multicolumn{3}{|c|}{ Ever had sexual intercourse } \\
\hline Yes & 719 & 92.7 \\
\hline No & 57 & 7.3 \\
\hline \multicolumn{3}{|c|}{ Initiated sexual intercourse (719) } \\
\hline By consent & 702 & 97.8 \\
\hline By force & 17 & 2.2 \\
\hline \multicolumn{3}{|c|}{ Attempt of forced sex and escape } \\
\hline Yes & 308 & 39.7 \\
\hline No & 468 & 60.3 \\
\hline \multicolumn{3}{|l|}{ Forced sex by $(n=17)$} \\
\hline Student friends/peer & 14 & 82.3 \\
\hline Teacher & 3 & 17.7 \\
\hline \multicolumn{3}{|c|}{ Place where forced sex performed } \\
\hline At home & 1 & 6.0 \\
\hline In hotel & 10 & 59.0 \\
\hline Unknown place & 6 & 35.3 \\
\hline \multicolumn{3}{|l|}{ Year of forced sex } \\
\hline 2007-2009 & 3 & 17.7 \\
\hline 2010-2012 & 14 & 82.3 \\
\hline \multicolumn{3}{|c|}{ Pregnancy after forced sex $(n=17)$} \\
\hline Yes & 8 & 47.0 \\
\hline No & 9 & 53.0 \\
\hline \multicolumn{3}{|c|}{ Outcome of unwanted pregnancy $(n=8)$} \\
\hline Gave birth & 0 & 0.0 \\
\hline Induced abortion & 8 & 100.0 \\
\hline
\end{tabular}

spondents 301 (38.8\%) followed by condom 110 (14.2\%) and injectables 51 (7\%). Healthcare workers 259 (53\%), friends 141 (29\%), teacher 45 (9\%) were sources of information; health workers were preferred sources of information. About two-third 328 (67\%) ever used modern contraceptives.

\subsection{Knowledge of Emergency Contraceptives}

More than two-third of the students 379 (72.2\%) knew about EC. Healthcare workers were the main source of information; 196 (25.3\%) reported OCPs and 95 (12.2\%) IUCD respectively. From the respondents who have known EC, 204 (26.3\%) reported EC to be taken after unprotected sexual intercourse and 170 (21.9\%) reported OCPs to be taken within 72 hours of unprotected post coital relation. Only 41 (10.8) had ever used EC methods (Table 3).

\subsection{Factors Associated with Knowledge and Utilization of Emergency Contraceptives}

Logistic regression analysis was carried out to determine the association between socio-demographic characteristics with knowledge and utilization of EC among the students. Accordingly, students aged 20 years and

Table 3. Knowledge and utilization of emergency contraceptive methods of Hawassa University female students, south Ethiopia, December 2012.

\begin{tabular}{|c|c|c|}
\hline Variables & Number & Percent \\
\hline \multicolumn{3}{|l|}{ Know modern contraceptive methods } \\
\hline Yes & 491 & 63.3 \\
\hline No & 285 & 36.7 \\
\hline \multicolumn{3}{|c|}{ Know emergency contraceptive methods (491) } \\
\hline Yes & 379 & 77.2 \\
\hline No & 112 & 21.8 \\
\hline \multicolumn{3}{|l|}{ Source of information on EC $(n=379)$} \\
\hline Health workers & 208 & 55.0 \\
\hline Friends/peer & 2 & 0.58 \\
\hline Teachers in the class & 22 & 6.0 \\
\hline Club in the university & 81 & 21.3 \\
\hline \multicolumn{3}{|l|}{ When EC are likely used? } \\
\hline After unprotected sexual intercourse & 204 & 54.0 \\
\hline When unwanted pregnancy occurs & 35 & 9.2 \\
\hline As ongoing contraceptive & 131 & 35.0 \\
\hline Do not know & 9 & 2.3 \\
\hline \multicolumn{3}{|l|}{ Methods known used as EC $(n=379)$} \\
\hline Pills & 196 & 52.0 \\
\hline Injectables & 1 & 0.26 \\
\hline Condom & 50 & 13.1 \\
\hline IUCD & 95 & 25.1 \\
\hline Withdrawal & 37 & 9.8 \\
\hline \multicolumn{3}{|c|}{ Know correct timing of EC as effective $(n=379)$} \\
\hline Yes & 302 & 80.0 \\
\hline No & 77 & 20.3 \\
\hline \multicolumn{3}{|l|}{ Ever used EC } \\
\hline Yes & 41 & 10.8 \\
\hline No & 338 & 89.2 \\
\hline
\end{tabular}


above were more likely to have knowledge on EC than those aged less than 20 years (AOR = 1.36 (95\% CI: 1.02 - 1.82)). As year of study increases knowledge of EC also increases; ever married female students had about 1.17 times more knowledge about EC than lower class students (AOR = 1.17 (95\% CI: 3.27 - 4.22)).

Female students living with their parents and peers in rented houses were 1.9 more likely to use EC than those living in-campus AOR = 1.9, (95\% CI: 1.7 - 3.31)). Students living \& living with peers in the rent house had used EC than living in-campus; moreover, $2^{\text {nd }}$-year and above female students more likely use EC than their juniors (Table 4).

\subsection{Sexual and Reproductive Health Characteristics and Knowledge and Utilization of EC}

Emergency contraceptive use was more among students whose age at menarche was 14-years and above (AOR = 1.42, (95\% CI: 1.23 - 2.14) than the earlier age (Table 5).

\section{DISCUSSION}

This study was aimed to assess the knowledge and utilization of EC among under graduate regular female students of Hawassa University.

Table 4. Socio-demographic characteristics and knowledge and utilization of EC among Hawassa University female students, south Ethiopia, December 2012.

\begin{tabular}{|c|c|c|c|c|}
\hline \multirow[t]{2}{*}{ Variables } & \multicolumn{2}{|c|}{ Knowledge of EC } & \multicolumn{2}{|c|}{ Utilization of EC } \\
\hline & COR (95\% CI) & AOR (95\% CI) & COR (95\% CI) & AOR (95\% CI) \\
\hline \multicolumn{5}{|l|}{ Age (years) } \\
\hline $15-19$ & 1.00 & 1.00 & 1.00 & 1.00 \\
\hline $20+$ & $0.723(0.54-0.96)$ & $1.36(1.01-1.82)^{* *}$ & $1.09(0.58-2.02)$ & $0.92(0.49-1.7)$ \\
\hline \multicolumn{5}{|l|}{ Religion } \\
\hline Orthodox & 1.00 & 1.00 & 1.00 & 1.00 \\
\hline Muslim & $0.58(0.19-1.7)$ & $0.56(0.23-1.34)$ & $3.53(0.56-2.2)$ & $0.3(0.004-1.8)$ \\
\hline Others & $0.85(0.49-1.45)$ & $0.48(0.21-1.10)$ & $0.97(0.22-4.3)$ & $0.9(0.2-4.2)$ \\
\hline \multicolumn{5}{|l|}{ Marital status } \\
\hline Single & 1.00 & 1.00 & 1.00 & 1.00 \\
\hline Married & $0.68(0.53-2.43)$ & $1.17(3.27-4.22)^{*}$ & $1.42(1.43-2.45)$ & $1.43(0.5-3.7)$ \\
\hline \multicolumn{5}{|l|}{ Residence } \\
\hline With peers in rented house & $0.50(0.08-2.9)$ & $0.97(0.22-5.21)$ & $1.75(1.46-3.6)$ & $1.9(1.7-3.31)^{*}$ \\
\hline \multicolumn{5}{|l|}{ Year of study } \\
\hline Year-1 & 1.00 & 1.00 & 1.00 & 1.00 \\
\hline Year-2 & $1.21(0.54-2.7)$ & $0.63(0.5-7.2)$ & $1.4(0.5-1.65)$ & $1.1(1.05-2.51)^{*}$ \\
\hline Year-3 & $1.29(0.51-3.24)$ & $1.82(0.29-11.2)$ & $1.6(1.3-2.43)$ & $1.49(1.3-3.2)^{* * *}$ \\
\hline Year-4 & $2.97(1.31-6.74)$ & $1.91(0.32-8.3)$ & $1.8(1.42-3.2)$ & $2.2(1.31-3.34)^{*}$ \\
\hline Year $>/=5$ & $7.81(2.16-28.18)$ & 1.95 (0.3 - 9.3) & $1.9(2.12-3.5)$ & $2.3(1.45-3.5)^{* * *}$ \\
\hline
\end{tabular}

${ }^{*}$ p-value $<0.05 ;{ }^{* *}$ p-value $<0.01$.

Table 5. Sexual and reproductive health characteristics and knowledge and utilization of EC among Hawassa University female students, south Ethiopia, December 2012.

\begin{tabular}{|c|c|c|c|c|}
\hline \multirow{2}{*}{ Variables } & \multicolumn{2}{|c|}{ Knowledge of EC } & \multicolumn{2}{|c|}{ Utilization of EC } \\
\hline & COR (95\% CI) & AOR (95\% CI) & COR (95\% CI) & AOR (95\% CI) \\
\hline $11-13$ & 1.00 & 1.00 & 1.00 & $1: 00$ \\
\hline 14 and above & $0.86(0.63-1.8)$ & $1.51(0.83-1.6)$ & $0.46(0.20-1.07)$ & $1.42(1.23-2.14)$ \\
\hline \multicolumn{5}{|l|}{ Sex by force } \\
\hline No & 1.00 & 1.00 & 1.00 & 1.00 \\
\hline \multicolumn{5}{|c|}{ Attempted forced sex/escaped } \\
\hline Yes & $1.08(0.81-1.4)$ & $1.07(0.8-1.45)$ & $1.01(0.54-1.9)$ & $1.62(0.01-1.56)$ \\
\hline No & 1.00 & 1.00 & 1.00 & 1.00 \\
\hline
\end{tabular}

${ }^{*}$ p-value $<0.05 ;{ }^{* *}$ p-value $<0.01$. 
Of the total respondents, 92.7\% have practiced sexual intercourse in their life time; this finding is higher than the study conducted on predictors of EC among female students of Adama University (43\%) [10]; this difference could be due to the higher number of married female students (22.4\%) while it was (14\%) for the Adama students. Among respondents who ever had sexual intercourse, $2.2 \%$ experienced forced sex and $47.1 \%$ resulted in unwanted pregnancy with the end outcome of induced abortion. The study done in Addis Ababa shows higher rate of unwanted pregnancy (73.5\%) but lower rate of induced abortion (71.7\%) and higher rate of unsafe abortion (29\%) [11]. The possible reasons for the high rate of safe abortion this study could be due to access to health facilities with skilled manpower. The rate of sexual violence with unintended sexual intercourse was high (82.3\%) in the period between 2010 and 2012. This result was higher than other study found in northwest Ethiopia among high school students (65.35\%) [12]; this result implies that there is low awareness of human right in the community and female empowerment was low as well. The main source of information for EC was health education from health workers (48.8\%); this finding is different from study done in Addis Ababa in which the main source of information for EC was mass media. The possible reason for this difference might be time constraint and low access for mass media. The majority of female students (95.1\%) knew correct timing for oral EC pills administration (within 72 hours) after unprotected sex; this result was higher than the study conducted in Haramiya University (18\%) [13]. The respondents believed that unintended sexual intercourse and unwanted pregnancy were the reproductive health problems for youth $(79.3 \%$ and $78.4 \%$ respectively). This shows that the youth are unaware of the possible complications due mainly to lack of information, education and communication regarding the issue. From total respondents only $10.8 \%$ had ever used EC; this result is lower than the study done among female students in Haramiya University [18\%] (14); limited access to services in the campus clinic might result in lower rate of emergency contraception utilization.

\section{CONCLUSION}

Only $48.8 \%$ of the female students had knowledge about emergency contraceptive; age, marital status and sex by force were associated with knowledge of emergency contraception. One among ten female students had ever used emergency contraception; residence and year of study were found to be predictors of emergency contraception utilization.

\section{RECOMMENDATIONS}

Information, Education and Communication campaigns and should be strengthened in the university about sexual and reproductive health services in general and emergency contraception in particular. Access to quality emergency contraceptive methods should be scaled up in higher education institutions.

\section{ACKNOWLEDGEMENTS}

We would like to extend our deepest gratitude to Health Sciences College of Hawassa University for its financial support. Our praise goes to all the study participants, data collectors and supervisors.

\section{REFERENCES}

[1] WHO (2007) Unsafe abortion global and regional estimate of incidence. 5th Edition, Geneva.

[2] WHO (2000) Maternal morbidity and mortality. 7th Edition, Geneva.

[3] William (1999) Unintended pregnancy. 4th Edition, Edinburgh Churchill Livingstone.

[4] Trussel, et al. (2006) Emergency contraception. 2nd Edition, Washington DC.

[5] Bell, et al. (2005) Emergency contraception. 2nd Edition, Churchill Livingstone.

[6] FMoH (2010) Health sector development programme-IV. 3-12.

[7] Gebreselasse, H. (2010) Sexual and reproductive health. Ethiopia Journal of Reproductive Health, 36, 16-25.

[8] Central Statistical Agency (CSA) [Ethiopia], MEASURE DHS, ICF Macro Calverton, Maryland, and USA (2011) Ethiopia demographic and health survey preliminary report. Addis Ababa, Ethiopia.

[9] Worku, A. (2001) Sexual violence among female higher education. African Medical Journal, 24, 12-15.

[10] Wegen, T. and Fikre, E. (2009) KAP on EC among female students at higher education Addis Ababa Ethiopia. 114115.

[11] Berhanu, D. (2006) Assessment of women KAP of EC among post abortion care seeking women in Addis Ababa Ethiopia. International Family Planning Perspectives, 22, 13-16.

[12] Paul, F.A. van (2003) Look contraception technology Johns Hopkins information programs. 7th Edition.

[13] Nasir, T. (2009) KAP of EC among female students of Jimma University. EJHD, 93-94. 